\title{
Profile of Inpatient Child and Adolescent Psychiatry in Sultanate of Oman
}

\author{
Ahmed Bait Amer'1, Rahab Al Aamri'2, Intisar Al-Ruhaili ${ }^{2}$ \\ ${ }^{1}$ Department of Behavioral Medicine, Sultan Qaboos University Hospital, Muscat, Oman \\ ${ }^{2}$ Psychiatry Department, Ministry of Health, Muscat, Oman \\ Email: ahmedsaid-777@hotmail.com
}

How to cite this paper: Amer, A.B., Al Aamri, R. and Al-Ruhaili, I. (2019) Profile of Inpatient Child and Adolescent Psychiatry in Sultanate of Oman. Open Journal of Nursing, 9, 449-457.

https://doi.org/10.4236/ojn.2019.94039

Received: March 10, 2019

Accepted: April 23, 2019

Published: April 26, 2019

Copyright $\odot 2019$ by author(s) and Scientific Research Publishing Inc. This work is licensed under the Creative Commons Attribution-NonCommercial International License (CC BY-NC 4.0). http://creativecommons.org/licenses/by-nc/4.0/ (c) (i) (8) Open Access

\begin{abstract}
Backgrounds: Mental illness is a common phenomenon at all ages. Various independent studies have shown that psychopathology is often expressed on a continuum from youth to adulthood. The aim of our study was to answer the question what are the problems that are likely to bring a child or an adolescent for the admission in the child and adolescent psychiatry Unit. Methods: The case records of all inpatient children and adolescents younger than 18 years, who were admitted to the child psychiatric unit at SQUH, Muscat, Sultanate of Oman over a period of 10 years between Jan 2007 and Dec 2017, were retrospectively reviewed in regard to sociodemographic data, referring specialties and reason for referral. Result: A total of 255 cases were admitted in child psychiatry unit in a period of $10 \mathrm{yrs}$, the average age was 14.15 years, 95\% patients were Omani nationals, $47.5 \%$ were male, 52.5 were females, $17.65 \%$ Acute and transient psychotic disorder, 13.7\% bipolar affective disorder, current episode manic without psychotic symptoms, $12.94 \%$ Intentional self-harm by other specified means and $12.55 \%$ schizophrenia, were the most common diagnoses observed in this population who needed inpatient care; the average length of stay in the majority of cases was less than 3 weeks. Conclusion: The child and adolescent inpatient unit of SQUH from where the data was collected happens to be the only child psychiatric admitting unit in Oman till the end of 2017 and can be considered as representative; the children and adolescence in-patient unit exemplifies a short-term care set-up.
\end{abstract}

\section{Keywords \\ Inpatient, Child, Adolescent}

\section{Background}

Numerous epidemiological studies have investigated the prevalence of mental 
illness in childhood and adolescence. Recent results have consistently shown that mental disorders are relatively common phenomena among children and adolescents, affecting at least $15 \%$ of the youth population in terms of point prevalence. The lifetime prevalence of mental disorders from childhood until the age of majority is somewhat higher, affecting on average $25 \%$ to $30 \%$ of young people at least once [1].

In Sultanate of Oman, the child and adolescent psychiatric inpatient services are still scarce. For the population of (4.6 million) according to the national estimate in 2017 [2], Citizens constitute 54\% of the population of Oman, with half of that population less than 25 years of age. Muscat is the largest city of Oman where the majority of the population resides, and the only city with Child and Adolescent Mental Health Services (CAMHS), "Overall, there is a scarcity of CAMHS in Oman" [3], with only one inpatient unit until the end of 2017 which was clearly insufficient. Although the majority of children with mental health problems are treated in community services, a comprehensive child and adolescent mental health service needs access to highly specialized provision including in-patient facilities [4].

A psychiatric disorder in childhood or adolescence has direct effects on the development and acquisition of skills relevant for coping and self-protection; it also substantially increases the likelihood in adulthood of experiencing a variety of health-related, economic and social disadvantages. More than half of all adult patients with mental illness retrospectively report that first symptoms occurred during childhood and adolescence and that there was a chronic progression into adulthood [1]. In general, inpatient psychiatric care has become "acute" care, to be used primarily for symptom stabilization in cases of mental health crisis [5].

The aim of our study is to answer the question what are the problems that are likely to bring a child or an adolescent for the admission in the child and adolescent psychiatry Unit.

The question which can arise is there any generally agreed criteria for when inpatient care is indicated? According to the review of the evidence in this suggests there are no absolute indications for inpatient care, but requires clinical judgment of the most appropriate care pathway after assessing their symptoms, motivation, level of family support and availability of community-based treatments. To guide clinical decision making, examples of when inpatient care is more likely to be indicated include:

1) A need for intensive assessment or treatment not available in the community.

2) Risk of self-harm or suicide.

3) Poor physical health requiring skilled medical care [6].

Also the Goals of hospitalization included symptom reduction, stabilization or/and alleviating anxiety of the parents. In all the cases, the primary psychiatric diagnosis influenced the decision regarding admission [7] [8]. most outcome studies of child and adolescent inpatient psychiatric care assess outcomes in terms of symptom reduction, quality of care indicators, such as rehospitaliza- 
tion, and service effectiveness outcomes, such as cost of services [9] [10] [11] [12] [13]. These studies generally report significant improvements in child behavior and emotional symptoms [14] [15].

\section{Methods}

\subsection{Study Population and Inclusion Criteria}

The Unit of Child and Adolescent Psychiatry in Sultan Qaboos University in sultanate of Oman is a specialized facility with a public service mandate for the Omani. It was the only hospital in the state with inpatient services for minors with mental health problems till the end of 2017. According to the estimate in 2017, Omani population was 4.6 million the following age structure shown as below with the absolute figures (estimate).

\subsection{Oman Age Structure}

In 2017 according to the estimates Oman had the following population age distribution:

- 0 - 14 years: $30.1 \%$.

- 15 - 24 years: $18.69 \%$.

- 25 - 54 years: $43.8 \%$.

- 55 - 64 years: $3.92 \%$.

- 65 years and over: $3.49 \%$.

As we notice from Figure 1 (48.7\%) were below the age of 25 years which means that almost half of the total population were young [16].

Our sample included all minors below age of 18 who received a psychiatric diagnosis and were treated as inpatients at least once at the Department of Behavioral medicine (Psychiatry) in the Child and Adolescent Unit in (sultan Qaboos University hospital) SQUH between Jan 2007 and Dec 2017. The sample is thus representative of the mental health inpatient treatment of minors in Oman. Electronic patient records were evaluated, and the primary psychiatric diagnosis was extracted. At the point of first diagnosis (data point one), all patients were minors, i.e. under the age of 18.

Diagnostic measures

Psychiatric diagnoses were based on ICD-10 Chapter V [17]. Inpatient cases prior to 2007 could not be included because electronic documentation had not yet been implemented. When a patient had more than one admission to the inpatient unit of the Department of Child and Adolescent Psychiatry, the main

\begin{tabular}{|l|l|}
\hline $30.1 \%$ & $65 \%$ \\
\hline$\square$ & - percentage of population under 15 \\
$\square$ & - percentage of population between 15 and 64 years old \\
\hline & - percentage of population $65+$
\end{tabular}

Figure 1. Oman age distribution. 
diagnosis of the first admission was used. If a patient had more than one admission as an adult, the diagnosis of the last admission was used for the study.

\subsection{Study Design}

The study is designed to assess former CAP-IP retrospectively. Electronic Data from all inpatient services in the SQUH were included.

\subsection{Statistical Methods}

All statistical analyses were performed with SPSS, version 21.

\section{Results}

A total of 255 cases were admitted in child psychiatry unit from Jan 2007 and Dec 2017 years. The patients aged from 3 - 17 years, and the average was 14.15 years (SD 3.346) (Table 1). A total of 242 (95\%) patients were Omani nationals. The Male were $(\mathrm{n}=121,47.5 \%)$, the Female were 134 (52.5) (Table 2). Psychiatric diagnoses were made according to the International Classificatory System of Diseases 10th Revision (ICD_10) [16]. The reason of admission of the children and adolescent is highlighted in Figure 2 \& Figure 3 and Table 3. Acute and transient psychotic disorder was the most common diagnosis made $17.65 \%$ ( $\mathrm{n}=$ 45 ) female 25, male 20, mean age 15, Bipolar affective disorder, current episode manic without psychotic symptoms $13.73 \%(\mathrm{n}=35)$ female 18 male 17 , mean age 16 , then Children with Intentional self-harm other specified means $12.94 \%$ ( $\mathrm{n}=$ 33) Female 25, male 8 mean age 16 which indicate that the females were more, this result simulates other studies [18], then schizophrenia $12.55 \%$ cases $(n=32)$ female 18 male 14, mean age 15, Other behavioral and emotional disorders with onset usually occurring in childhood and adolescence $10.20 \%(n=26)$ Female 9 male 17 , mean age 14, Severe depressive episode without psychotic symptoms (n $=11$ ), female 6, Male 5 mean age 16, Dissociative (conversion) disorder, unspecified $(\mathrm{n}=11)$ female 6 , male 5 mean age 15 , Other mental disorders due to

Table 1. Age of study group.

\begin{tabular}{cccccc}
\hline & N & Minimum & Maximum & Mean & Std. Deviation \\
\hline Age & 255 & 3 & 17 & 14.15 & 3.346 \\
\hline
\end{tabular}

Table 2. Nationality and gender.

\begin{tabular}{cc}
\hline Description & N (\%) \\
\hline Nationality & $242(95)$ \\
Omani & $13(5)$ \\
Expatriate & \\
Gender & $121(47.5)$ \\
Male & $134(52.5)$ \\
Female &
\end{tabular}


Table 3. Admission reasons and duration of admission.

\begin{tabular}{|c|c|c|c|c|c|c|c|}
\hline \multirow[t]{2}{*}{ Admission reasons } & \multirow[t]{2}{*}{ Total No. (\%) } & \multicolumn{2}{|c|}{ Sex } & \multirow[t]{2}{*}{ Mean age } & \multicolumn{3}{|c|}{ Admission duration } \\
\hline & & Female & Male & & Minimum & Maximum & Mean \\
\hline F23 Acute and transient psychotic disorder & $45(17.6)$ & 25 & 20 & 15 & 1 & 48 & 11 \\
\hline $\begin{array}{l}\text { F31.1 Bipolar affective disorder, current } \\
\text { episode manic without psychotic symptoms }\end{array}$ & $35(13.7)$ & 18 & 17 & 16 & 3 & 51 & 16 \\
\hline $\begin{array}{l}\text { X83 Intentional self-harm by other specified } \\
\text { means }\end{array}$ & $33(12.9)$ & 25 & 8 & 16 & 1 & 49 & 8 \\
\hline F20 Schizophrenia & $32(12.5)$ & 18 & 14 & 15 & 1 & 95 & 19 \\
\hline $\begin{array}{l}\text { F98 Other behavioral and emotional disorders } \\
\text { with onset usually occurring in childhood and } \\
\text { adolescence }\end{array}$ & $26(10.2)$ & 9 & 17 & 14 & 1 & 35 & 7 \\
\hline $\begin{array}{l}\text { F32.2 Severe depressive episode without } \\
\text { psychotic symptoms }\end{array}$ & $11(4.3)$ & 6 & 5 & 16 & 1 & 29 & 8 \\
\hline $\begin{array}{l}\text { F41.9 Dissociative (conversion) disorder, } \\
\text { unspecified }\end{array}$ & $11(4.3)$ & 6 & 5 & 15 & 1 & 29 & 7 \\
\hline $\begin{array}{l}\text { F6 Other mental disorders due to brain damage } \\
\text { and dysfunction and to physical disease }\end{array}$ & $10(3.6)$ & 4 & 6 & 13 & 1 & 11 & 4 \\
\hline $\begin{array}{l}\text { F33.3 Recurrent depressive disorder, current } \\
\text { episode severe with psychotic symptom }\end{array}$ & $8(3.1)$ & 5 & 3 & 15 & 5 & 29 & 14 \\
\hline F49.1 Anxiety disorder, unspecified & $4(1.6)$ & 2 & 2 & 13 & 2 & 30 & 12 \\
\hline $\begin{array}{l}\text { F89 Unspecified disorder of psychological } \\
\text { development }\end{array}$ & $3(1.2)$ & 1 & 2 & 7 & 1 & 2 & 1 \\
\hline F90.0 Disturbance of activity and attention & $3(1.2)$ & 1 & 2 & 7 & 1 & 1 & 1 \\
\hline F50 Anorexia nervosa & $1(0.4)$ & & 1 & 14 & & & 1 \\
\hline F42.0 Obsessive-compulsive disorder & $1(0.4)$ & 1 & & 15 & & & 10 \\
\hline $\begin{array}{l}\text { F } 09 \text { Unspecified organic or symptomatic } \\
\text { mental disorder }\end{array}$ & $1(0.4)$ & & 1 & 17 & & & 8 \\
\hline Others & $31(12.2)$ & 13 & 18 & 8 & 1 & 29 & 2 \\
\hline
\end{tabular}

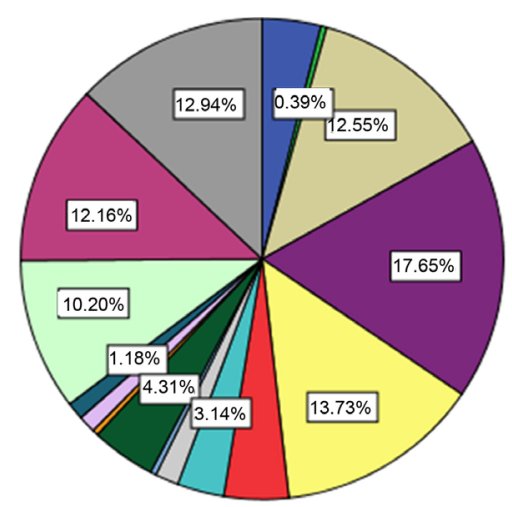

Admission reasons

Fig: Distribution of admission diagnosis groups (n 255), F23: Acute and transient psychotic disorder, F20: Schizophrenia, F31.1: Bipolar affective disorder, current episode manic without psychotic symptoms, F33.3: Recurrent depressive disorder, current episode severe with psychotic symptom, F32.2: Severe depressive episode without psychotic symptoms, F41.9: Anxiety disorder, unspecified, F42: Obsessivecompulsive disorder, F44.9: Dissociative [conversion] disorder, unspecified, F50.0: Anorexia nervosa, F09: Unspecified organic or symptomatic mental disorder, F90.0: Disturbance of activity and attention, F06: Other mental disorders due to brain damage and dysfunction and to physical disease, X83: intentional self harm by other specified means, F89: Unspecified disorder of psychological development, F98: Other behavioural and emotional disorders with onset usually occurring in childhood and adolescence

Figure 2. Admission reason. 


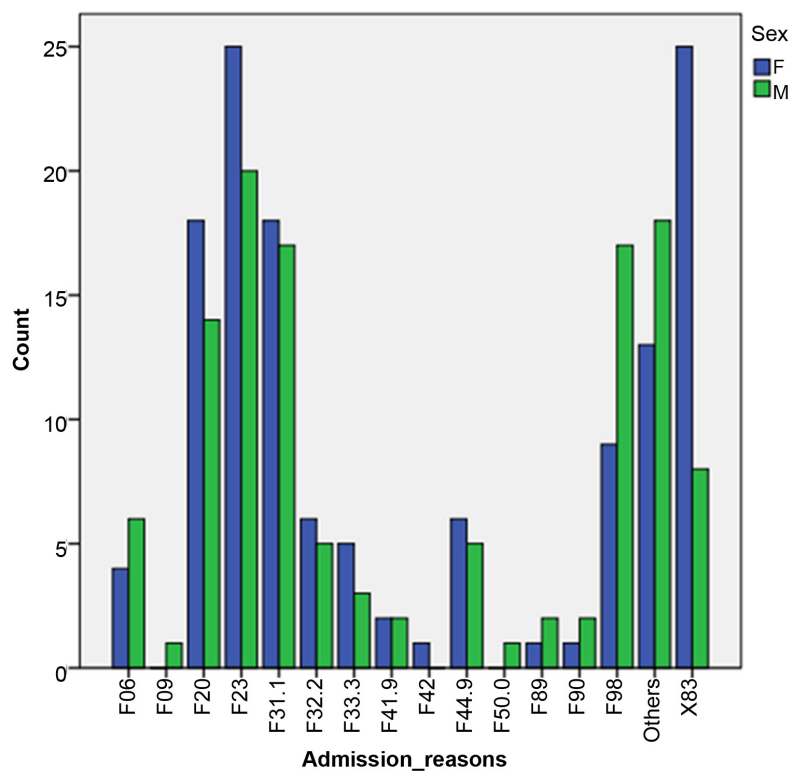

Fig: Distribution of admission diagnosis groups (n 255), F23: Acute and transient psychotic disorder, F20: Schizophrenia, F31.1: Bipolar affective disorder, current episode manic without psychotic symptoms,

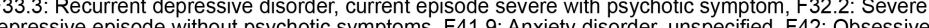

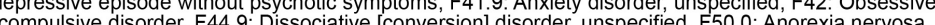
F09: Unspecified organic or symptomatic mental disorder F90 0. Disturbance of activity and attention, F06: Other mental disorders due to brain damage and dysfunction and to physical disease, X83: intentional self harm by other specified means, F89: Unspecified disorder of psychological development, F98: Other behavioural and emotional disorders with onset usually occurring in childhood and adolescence

Figure 3. Male to female ratio in relation to the admission reasons.

brain damage and dysfunction and to physical disease $(\mathrm{n}=10)$ female 4 , male 6 , mean age 13, Recurrent depressive disorder, current episode severe with psychotic symptom $(\mathrm{n}=8)$, female 5 , male 3 , mean age 15 , Anxiety disorder, unspecified $(\mathrm{n}=4)$, female 2 , male 2 , mean age 13 , Unspecified disorder of psychological development $(\mathrm{n}=3)$ Female 1, male 2, mean age 7, Disturbance of activity and attention $(\mathrm{n}=3)$ female 1 , male 2 , mean age 7 , Anorexia nervosa $(\mathrm{n}=1)$, female 0 , male 1 mean age 14, Obsessive compulsive disorder female 1 , male 1 , mean age 15 , Unspecified organic or symptomatic mental disorder $(n=1)$, female 1 male 0 , mean age 17, others include cases which was admitted on an elective basis, mostly for observation, diagnostic clarification $(n=31)$ female 13 , male 18 , mean age 8 , from the above result the mean length of the stay of the Majority of the children is less than 3 weeks.

\section{Discussion}

All minors who received a psychiatric inpatient diagnosis in Oman over a period of nearly one decade were included in our sample. The Department of Child and Adolescent Psychiatry in SQUH is the only facility to admit children for the state till the end of 2017. Cases were admitted primarily due to problems related to a specific psychiatric diagnosis. The average duration of stay of 3 weeks is an indication that the child and adolescent inpatient unit of SQUH functions as short-term care facility only, with the specific goal of "symptom reduction"; at the same time it is "user friendly" as the decisions regarding admission and dis- 
charge are discussed with the family Also continuity of care is ensured through the outpatient services run by the same unit/personnel and to a less extent through liaison with other referring agencies. Hence the admission is only a phase and not an end in itself [6]. All of the patients (100\%) were school-age children, a finding similar to that of other studies. This might be attributed principally to school problems, and secondarily to disturbed cognitive functions [18]. Females exceeding males in the Intentional self-harm (females $75.7 \%$, males $24.2 \%)$, these patterns of gender distribution in the Intentional self-harm, is consistent with a pattern of youth suicides reported in several countries are also well known in population-based epidemiological studies [19] [20]. Findings showed that substance use was not rated among this young group sample, Because hospital policy not allow the admission of substance use cases, the number of Children with Disturbance of activity and attention was small (1.2\%) because usually they did not be admitted unless they had comorbidity with psychosis, it is the same with Obsessive compulsive disorder, Anorexia nervosa usually admitted in the medical word this can be explained why only we have $(0.4 \%)$ in our inpatient, others (12.2\%) were admitted on an elective basis, mostly for observation, diagnostic clarification 24 cases were admitted for MRI, 3 cases for CT scan 2 cases for EEG, and cases 2 for observation most of them were admitted in pediatric wards under the coverage of child and adolescent unite.

\section{The Strength and Limitations}

This is the first empirical study to assess the profile of admission among inpatients of a child and adolescent psychiatric unit in Oman. This study clarifies what are the reasons which leads to admission, noticed from the above-mentioned result that the mean age of most of the admitted children and adolescent in CAP unite were above 12 because of the hospital policy not allowed to admit children below 12 in the psychiatry inpatient this is a limitation which can be overcomes in the future by building more expanded unit with full facility which allow admission of any age of the minors till below 18 . The second limitation we lacked a comparison or control group, which is a common problem for this type of study [21].

\section{Conclusion}

The child and adolescent inpatient unit of SQUH from where the data was collected happens to be the only child psychiatric admitting unit in Oman till the end of 2017 and can be considered as representative; the children and adolescence in-patient unit exemplifies a short-term care set-up. However, the inpatient child psychiatry service needs to be expanded in order to become an integrative unit with expert trained multidisciplinary team to parallel the needs of the population.

\section{Funding}

No external funding was used in this study. 


\section{Authors' Contributions}

All of the three authors were contributing in the research.

\section{Consent for Publication}

Not applicable.

\section{Ethics Approval and Consent to Participate}

The study was approved by the Ethics Committee of the SQU. Individual consent was unnecessary because this study deals with a retrospective analysis of existing patient data.

\section{Conflicts of Interest}

The authors declare that they have no competing interests.

\section{References}

[1] Fuchs, M., et al. (2016) Child and Adolescent Psychiatry Patients Coming of Age: A Retrospective Longitudinal Study of Inpatient Treatment in Tyrol. BMC Psychiatry, 16, 225.

[2] https://www.ncsi.gov.om

[3] Mirza, H. (2018) Child and Adolescent Mental Health Services in Oman. London Journal of Primary Care, 10, 121-122.

[4] Gowers, S.G. and Cotgrove, A.J. (2004) The Future of In-Patient Child and Adolescent Mental Health Services. The British Journal of Psychiatry, 183, 479-480.

[5] Goldman, W., McCulloch, J. and Sturm, R. (1998) Costs and Use of Mental Health Services before and after Managed Care. Health Affairs, 17, 40-52. https://doi.org/10.1377/hlthaff.17.2.40

[6] Indig, D., Gear, C. and York, A. (2017) CGA Consulting. Sax Institute.

[7] Bharath, S., Srinath, S., Seshadri, S. and Girimji, S. (1997) Child and Adolescent Psychiatry In-Patient Facility. Indian Journal of Psychiatry, 64, 829-832.

[8] Hanssen-Bauer, K., et al. (2003) Admissions to acute Adolescent Psychiatric Units: A Prospective Study of Clinical Severity and Outcome. BJP, 183, 479-480.

[9] Chung, W., Edgar-Smith, S., Palmer, R.B., Bartholomew, E. and Delambo, D. (2008) Psychiatric Rehospitalization of Children and Adolescents: Implications for Social Work Intervention. Child Adolescent Social Work Journal, 25, 483-496. https://doi.org/10.1007/s10560-008-0147-8

[10] Parmelee, D.X., Cohen, R., Nemil, M., Best, A.M., Cassell, S. and Dyson, F. (1995) Children and Adolescents Discharged from Public Psychiatric Hospital: Evaluation of Outcome in a Continuum of Care. Journal of Child and Family Studies, 4, 43-55. https://doi.org/10.1007/bf02233953

[11] Fontanella, C.A. (2008) The Influence of Clinical, Treatment, and Healthcare System Characteristics on Psychiatric Readmission of Adolescents. American Journal of Orthopsychiatry, 78, 187-198.

[12] Hoagwood, K., Jensen, P.S., Petti, T. and Burns, B.J. (1996) Outcomes of Mental Health Care for Children and Adolescents: A Comprehensive Conceptual Model. Journal of the American Academy of Child \& Adolescent Psychiatry, 35, 1055-1063. 
https://doi.org/10.1097/00004583-199608000-00017

[13] Pottick, K.J., Hansell, S., Miller, J.E. and Davis, D.M. (1999) Factors Associated with Inpatient Length of Stay for Children and Adolescents with Serious Mental Illness. Social Work Research, 23, 213-224. https://doi.org/10.1093/swr/23.4.213

[14] Gavidia-Payne, S., Littlefield, L., Hallgren, M., Jenkins, P. and Coventry, N. (2003) Outcome Evaluation of a Statewide Inpatient Mental Health Unit. Australian and New Zealand Journal of Psychiatry, 37, 204-211. https://doi.org/10.1046/j.1440-1614.2003.01124.x

[15] Swadi, H. and Bobier, C. (2005) Hospital Admission in Adolescents with Acute Psychiatric Disorder: How Long Should It Be? Australasian Psychiatry, 13, 165-168. https://doi.org/10.1080/j.1440-1665.2005.02181.x

[16] https://en.wikipedia.org/wiki/Demographics_of_Oman

[17] https://www.who.int/classifications/icd

[18] Al-Sharbati, M.M., Al-Hussaini, A.A. and Antony S.X. (2003) Profile of Child and Adolescent Psychiatry in Oman. Saudi Medical Journal, 24, 391-395.

[19] Ravens-Sieberer, U., Wille, N., Erhart, M., Bettge, S., Wittchen, H.U., Rothenberger, A., Herpertz-Dahlmann, B., Resch, F., Holling, H., Bullinger, M., et al. (2008) Prevalence of Mental Health Problems among Children and Adolescents in Germany: Results of the BELLA Study within the National Health Interview and Examination Survey. European Child Adolescent Psychiatry, 17, 22-33. https://doi.org/10.1007/s00787-008-1003-2

[20] Fuchs, M., Bosch, A., Hausmann, A. and Steiner, H. (2013) "The Child is Father of the Man": Review of Literature on Epidemiology in Child and Adolescent Psychiatry. Zeitschrift für Kinder- und Jugendpsychiatrie und Psychotherapie, 41, 45-57. https://doi.org/10.1024/1422-4917/a000209

[21] Setoya, Y., et al. (2011) Evaluating Outcomes of the Child and Adolescent Psychiatric Unit: A Prospective Study. International Journal of Mental Health Systems, 5, 7.

\section{Abbreviations}

CAD: child and/or adolescent diagnosis

CAP: child and adolescent psychiatry

CAP-IP: child and adolescent psychiatry inpatients

SUD: substance use disorder 